\title{
FAKTOR-FAKTOR YANG BERHUBUNGAN DENGAN KELELAHAN KERJA PADA PERAWAT DI RUANG RAWAT INAP RUMAH SAKIT UMUM GMIM PANCARAN KASIH MANADO
}

\author{
Deivy Tenggor \\ Linnie Pondaag \\ Rivelino S. Hamel \\ Program Studi Ilmu Keperawatan Fakutas Kedokteran \\ Universitas Sam Ratulangi \\ Email : tenggordeivy@gmail.com
}

\begin{abstract}
Nurse is an important part of patient care so the nurse is not scarcely to provide optimal servants so that sometimes causes fatigue to nurses caused by various factors including age, years of service and workload, causing fatigue to nurses. Research Objectives: To find out the factors of relating for the fatigue of nurse work at the RSU GMIM Pancaran Kasih Manado. Research method: The mothod is using a cross sectiona research, the total population taken as many as 135 people with many samples taken is $40 \%$ of the total population. Research Results: Based on the results of statistical tests with Chi Square test the relationship of age to fatigue was obtained that the p-value $0,006<\alpha 0,05$, the relationship between work period and fatigue was obtained that the value was 0,114> $\alpha 0,05$, and the relationship between workload and fatigue is obtained that the p-value is 0,031< $\alpha 0,05$. Conclusions based on data can be concluded that there is a relationship between age and fatigue, the length of work with fatigue there is no relationship, while the workload with fatigue found a relationship.
\end{abstract}

Keywords: Age, Workload, WorkPperiod, Nurse Fatigue

Abstrak : Perawat merupakan salah satu bagian penting dalam perawatan pasien sehingga tak jarang perawat dituntut untuk memberikan pelayan yang optimal sehingga terkadang menyebabkan kelelahan pada perawat yang disebabkan oleh berbagai faktor antara lain umur, masa kerja dan beban kerja sehingga menyebabkan kelelahan pada perawat. Tujuan Penelitian: Mengetahui faktor-faktor yang berhubungan dengan kelelahan kerja perawat di RSU GMIM Pancaran Kasih Manado. Metode Penelitian: Metode yang digunakan adalah penelitian cross sectional, dengan menggunakan uji chi-square jumlah populasi yang di ambil sebanyak 135 orang Perawat Banyaknya sampel yang diambil yaitu $40 \%$ dari total populasi. Hasil Penelitian : Berdasarkan hasil uji statistik dengan uji Chi Square hubungan usia dengan kelelahan diperoleh bahwa nilai p-value $0,006<\alpha 0,05$, hubungan masa kerja dengan kelelahan diperoleh bahwa nilai 0,114> $\alpha$ 0,05, dan hubungan beban kerja dengan kelelahan diperoleh bahwa nilai p $0,031<\alpha \quad 0,05$. Kesimpulan berdasarka data dapat disimpulkan adanya hubungan antara usia dengan kelelahan, lama kerja dengan kelelahan tidak adanya hubungan, sedangkan beban kerja dengan kelelahan didapati adanya hubungan.

Kata Kunci : Usia, Masa Kerja, Beban Kerja, Kelelahan Perawat 


\section{PENDAHULUAN}

Rumah sakit merupakan bagian integral dari suatu organisasi sosial dan kesehatan dengan fungsi menyediakan pelayanan paripurna (komprehensif), penyembuhan penyakit (kuratif), dan pencegahan penyakit (preventif). Berdasarkan UndangUndang No.44 Tahun 2009 tentang Rumah sakit adalah institusi pelayanan kesehatan yang menyelenggarakan pelayanan kesehatan bagi perorangan secara menyeluruh dan paripurna dengan menyediakan pelayanan rawat inap, rawat jalan, dan gawat darurat (World Health Organization (WHO 2014).

Keputusan Menteri kesehatan Republik Indonesia No.340/MENKES/PER/III/2010, Rumah sakit adalah institusi pelayanan kesehatan yang menyelenggarakan pelayanan kesehatan perorangan secara paripurna yang menyediakan pelayanan rawat inap, rawat jalan, dan gawat darurat. Salah satu faktor yang mendukung keyakinan diatas adalah kenyataan yang dapat dilihat dari setiap instalasi pelayanan kesehatan dirumah sakit, dimana paratenaga kesehatan selama 24 jam harus berada disisi pasien adalah tenaga perawat (Anis Wahyuningsih, 2003).

Keperawatan merupakan bentuk pelayanan profesional berupa pemenuhan kebutuhan dasar yang diberikan kepada individu yang sehat maupun sakit yang mengalami gangguan fisik, psikis, dan sosial agar dapat mencapai derajat kesehatan yang optimal (Nursalam, 2008). Laporan WHO (2016) menunjukkan bahwa pada tahun 2013 tenaga kesehatan dunia ada 43 juta. Ini termasuk 9,8 juta dokter, 20,7 juta perawat/bidan, dan sekitar 13 juta pekerja kesehatan lainnya. Perawat merupakan tenaga kesehatan terbanyak. Menurut Kemenkes (2016), total sumber daya manusia kesehatan di rumah sakit di Indonesia pada tahun 2015 sebanyak 493.856 orang yang terdiri dari 322.607 orang tenaga kesehatan $(65,32 \%)$ dan 171.249 orang tenaga penunjang kesehatan
(34,68\%). Secara kuantitas, jumlah tenaga kesehatan terbanyak yaitu perawat sebanyak 147.264 orang $(45,65 \%)$. Oleh karena itu, diharapkan banyaknya jumlah perawat di rumah sakit khususnya sebagai perawat rawat inap harus mempunyai kualitas yang baik.

Kelelahan adalah salah satu faktor yang dapat mengurangi kapasitas kerja dan ketahanan tubuh pekerja. Terdapat dua jenis kelelahan yaitu kelelahan otot dan kelelahan umum. Kelelahan otot merupakan tremor pada otot. Kelelahan umum ditandai dengan berkurangnya kemauan untuk bekerja yang sebabnya adalah persyaratan psikis. Penyebab kelelahan umum adalah monotoni, intensitas, dan lamanya kerja mental dan fisik, keadaan lingkungan (Suma`mur, 2009). Kelelahan kerja akan menurunkan kinerja dan menambah tingkat kesalahan kerja. Meningkatnya kesalahan kerja akan memberikan peluang terjadinya kecelakaan kerja dalam industri. Pembebanan otot secara statispun (static muscular loading) jika dipertahankan dalam waktu yang cukup lama akan mengakibatkan RSI (Repetition Strain Injuries ), yaitu nyeri otot, tulang, tendon, dan lain-lain yang diakibatkan oleh jenis pekerjaan yang bersifat berulang (Nurmianto, 2005).

Invistigasi di beberapa Negara menunjukan bahwa kelelahan (fatigue) memberi kontribusi yang signifikan terhadap kecelakaan kerja (Eraliesa, 2008). Kelelahan kerja memberi kontribusi $50 \%$ terhadap terjadinya kecelakaan kerja (Setyowati, 2007). Data dari International Labour Organization (ILO) (2003) menunjukan bahwa hampir setiap tahun sebanyak dua juta pekerja meninggal dunia karena kecelakaan kerja yang disebabkan oleh faktor kelelahan. Penelitian tersebut menyatakan dari 58.115 sampel, sekitar 18.828 sampel menderita kelelahan yaitu sekitar 32,8\% dari keseluruhan sampel (Baiduri,2008). 
Haryono, dkk (2009) melakukan penelitian tentang hubungan antara beban kerja, stress kerja, dan tingkat konflik dengan kelelahan kerja perawat di Rumah sakit islam Yogjakarta PDHI Kota Yogjakarta tahun 2009, bahwa sebagian besar perawat merasa lelah dengan frekuensi $55,77 \%$ perawat, $61,54 \%$ perawat mempunyai tingkat konflik yang sedang, $82,70 \%$ perawat mempunyai tingkat konflik yang berat. Hasil survei sementara didapati jumlah seluruh perawat di RSU Pancaran Kasih GMIM Manado sebanyak 192 orang. Jumlah perawat terbanyak bekerja di bagian rawat inap yaitu sebanyak 135 orang (perawat pelaksana) di 12 ruang rawat inap.

Hasil wawancara secara umum terhadap 7 perawat pelaksana yang bertugas di ruang rawat inap di RSU Pancaran Kasih GMIM Manado, didapatkan bahwa 4 diantaranya sudah berusia diatas 40 tahun dimana perawat memasuki masa dewasa akhir dimana fungsi-fungsi tubuh terjadi penurunan dan masa kerja yang sudah lebih dari 5 tahun, mengatakan bahwa terkadang perawat merasa kurang bersemangat, merasa ngantuk, bahkan hilangnya semangat kerja karena tuntutan pekerjaan yang semakin banyak diruangan, ditambah dengan rasio perawat dan pasien yang tidak sesuai serta tuntutan kerja dari atasan membuat perawat merasa kelelahan dalam melakukan kerja, tak jarang menimbulkan rasa ngantuk, sedangkan 3 perawat yang berusia 30 tahun dengan masa kerja $<5$ tahun mengatakan sejauh ini pekerjaan yang diberikan masih dapat diselesaikan dengan baik walaupun kadang selesai pekerjaan sudah lewat shiff dengan tuntutan kerja yang begitu banyak. Dari latar belakang tersebut peneliti tertarik untuk melakukan penelitian tentang faktorfaktor yang berhubungan dengan kelelahan kerja pada perawat di Rumah Sakit Umum GMIM Pancaran Kasih Manado.

\section{METODE PENELITIAN}

Desain penelitian ini menggunakan penelitian cross sectioanal. Penelitian cross sectional adalah jenis penelitian yang menekankan pada pengukuran atau observasi data variabel independen dan dependen hanya satu kali, pada satu saat (Nursalam, 2008). Penelitian telah dilaksanakan di ruang rawat inap Rumah sakit Umum GMIM Pancaran Kasih Manado.Penelitian ini telah dilaksanakan pada bulan September 2018 sampai bulan Desember 2018. Populasi penelitian ini adalah seluruh tenaga perawat di ruang rawat inap Rumah Sakit Umum GMIM Pancaran Kasih Manado sebanyak 135 orang.

Sampel dalam penelitian ini di ambil dengan teknik simpel random sampling. Pada penelitian ini banyaknya sampel yang diambil adalah 54 responden. Kriteria Inklusi: Kriteria inklusi pada penelitian ini adalah perawat yang bekerja di ruang rawat inap Rumah Sakit Umum GMIM Pancaran Kasih Manado, perawat yang bersedia menjadi responden dengan mengisi surat kesediaan menjadi responden. Instrumen penelitian: Instrumen yang digunakan dalam penelitian ini adalah kuesioner. Kuesioner yang digunakan berisi tentang usia, masa kerja, beban kerja, dan kelelahan kerja. Menurut Depkes RI (2009) mengkategorikan usia> 26 tahun merupakan masa remaja akhir, 26-35 tahun masa dewasa awal dan > 35 tahun masa dewasa akhir. Masa kerja dihitung sejak perawat mulai bekerja di rumah sakit tersebut sampai saat penelitian dengan kriteria $<5$ tahun yang bisa dikatakan perawat yang pengalaman kerjanya baru sedikit / pemula dan $>5$ tahun yang bisa dikatakan perawat yang telah memiliki pengalaman yang cukup ( Nursalam, 2016). Kuesioner beban kerja ini sudah dipakai dalam penelitian Nursalam (2016). Kuesioner beban kerja terdiri dari 13 pertanyaan dengan menggunakan skala Likert $(1$ = sangat tidak setuju, 2 = tidak 
setuju, 3 = setuju, 4 = sangat setuju). Kelelahan kerja peneliti menggunakan kuesioner buku KAUPK2 ( Kuesioner Alat Ukur Perasaan Kelelahan Kerja). Dimana kuesioner ini sudah dipakai dalam penelitian Baroka (2017). Kuesioner ini disusun oleh Setyawati yang sudah diuji validitas dan reliabilitasnya. Jumlah keseluruhan kuesioner ini terdiri dari 17 item pertanyaan. Setiap jawaban diberi skor dengan ketentuan ( skor 1: diberikan untuk jawaban "Ya" dan skor 2: diberikan untuk jawaban "Tidak"

\section{HASIL dan PEMBAHASAN Karakteristik Responden}

Tabel 1.Karakteristik responden berdasarkan jenis kelamin

\begin{tabular}{lll}
\hline Jenis Kelamin & $\mathrm{n}$ & $\%$ \\
\hline Laki- laki & 6 & 11.1 \\
Perempuan & 48 & 88.9 \\
\hline Total & 54 & 100 \\
\hline
\end{tabular}

Sumber Data Primer : 2018

Data pada tabel 1 menunjukan bahwa dari 54 responden yang paling banyakberjenis kelamin perempuan 48 responden $(88.9 \%)$ dan laki-laki 6 responden $(11.1 \%)$.

\section{Analisis Univariat}

Tabel 2.Karateristik responden berdasarkan umur

\begin{tabular}{lll}
\hline Usia & $\mathrm{n}$ & $\%$ \\
\hline$<26$ Tahun & 18 & 33.3 \\
26-35 Tahun & 32 & 59.3 \\
$>$ 35 Tahun & 4 & 7.4 \\
\hline Total & 54 & 100 \\
\hline
\end{tabular}

Sumber Data Primer: 2018

Hasil dari distribusi tabel 2 ditunjukkan bahwa umur paling banyak yaitu 26-35 tahun yaitu 32 responden $(69.3 \%)$ dan paling sedikit umur $>35$ tahun yaitu 4 responden $(7.4 \%)$.
Tabel 3. Karateristik responden berdasarkan masa kerja

\begin{tabular}{lcl}
\hline Masa Kerja & $\mathrm{n}$ & $\%$ \\
\hline$\leq 5$ Tahun & 37 & 68,5 \\
$>5$ Tahun & 17 & 31.5 \\
\hline Total & 54 & 100 \\
\hline
\end{tabular}

Sumber Data Primer: 2018

Berdasarkan hasil distribusi tabel 3 ditunjukkan bahwamasa kerja paling banyak yaitu $<5$ tahun yaitu 37 responden $(68.5 \%)$ dan paling sedikit $>5$ tahun yaitu 17 responden $(31.5 \%)$.

Tabel 4. Karateristik responden berdasarkan beban kerja

\begin{tabular}{lll}
\hline Beban Kerja & $\mathrm{n}$ & $\%$ \\
\hline Berat & 6 & 11.1 \\
Sedang & 26 & 48.2 \\
Ringan & 22 & 48.7 \\
\hline Total & 54 & 100 \\
\hline
\end{tabular}

Sumber Data Primer: 2018

Berdasarkan tabel 4 ditunjukkan bahwa beban kerja paling banyak yaitu sedang yaitu 26 responden $(48.2 \%)$ dan paling sedikit berat yaitu 6 responden (11.1\%).

Tabel 5.Karateristik responden berdasarkan kelelahan

\begin{tabular}{lll}
\hline Kelelahan & $\mathrm{n}$ & $\%$ \\
\hline Kelelahan & 17 & 31.5 \\
Tidak Lelah & 37 & 68.5 \\
\hline Total & 54 & 100 \\
\hline \multicolumn{2}{l}{ Sumber Data } \\
\end{tabular}

Berdasarkan tabel 5 ditunjukkan bahwa kelelaha kerja pada perawat paling banyak tidak lelah yaitu 37 responden $(68.5 \%)$ dan paling sedikit kelelahan yaitu 17 responden $(31.5 \%)$. 


\section{Analisis Bivariat}

Tabel 6. Hubungan Usia Dengan Kelelahan Perawat

\begin{tabular}{cccccccc}
\hline \multirow{2}{*}{ Umur } & \multicolumn{6}{c}{ Kelelahan Perawat } & \multirow{2}{*}{ Nilai p } \\
\cline { 2 - 6 } & Kelelahan & \multicolumn{2}{c}{ Tidak Lelah } & \multicolumn{2}{c}{ Total } & \\
\cline { 2 - 7 } & $\mathrm{n}$ & $\%$ & $\mathrm{n}$ & $\%$ & $\mathrm{n}$ & $\%$ & \\
\hline <26 Tahun & 2 & 3.7 & 16 & 29.6 & 18 & 33.3 & \\
26-35 Tahun & 12 & 22.2 & 20 & 37.1 & 32 & 59.3 & \\
>35 Tahun & 3 & 5.6 & 1 & 1.8 & 4 & 7.4 & \\
\hline Total & 17 & 31.6 & 37 & 68.5 & 54 & 100 & \\
\hline
\end{tabular}

Sumber Data Primer: 2018

Berdasarkan hasil uji statistik dengan menggunakan uji Chi Square diperoleh bahwa nilai $\mathrm{p} 0,006<\alpha 0,05$. Dengan demikian Ho ditolak dan $\mathrm{Ha}$ diterima, artinya terdapathubungan antara umur dengan kelelahan kerja perawat.

Tabel 7. Hubungan Masa Kerja Dengan Kelelahan Perawat

\begin{tabular}{cccccccc}
\hline & \multicolumn{6}{c}{ Kelelahan Perawat } & \multirow{2}{*}{ Nilai p } \\
\cline { 2 - 6 } Masa Krja & \multicolumn{1}{c}{ Kelelahan } & \multicolumn{2}{c}{ Tidak Lelah } & \multicolumn{2}{c}{ Total } & \\
\cline { 2 - 7 } & $\mathrm{n}$ & $\%$ & $\mathrm{n}$ & $\%$ & $\mathrm{n}$ & $\%$ & \\
\hline$\leq 5$ Tahun & 8 & 14.8 & 29 & 53.7 & 37 & 68.5 & \\
\hline > 5 Tahun & 9 & 16.7 & 8 & 14.8 & 17 & 31.5 & 0.114 \\
\hline Total & 17 & 31.5 & 37 & 68.5 & 54 & 100 & \\
\hline
\end{tabular}

Sumber Data Primer: 2018

Hasil uji statistik dengan menggunakan uji Chi Square diperoleh bahwa nilai 0,114> $\alpha$ 0,05.Dengan demikian Ho diterima dan Ha ditolak, artinya tidak ada hubungan antaramasa kerja dengan kelelahan kerja perawat.

Tabel 8. Hubungan Beban Kerja Dengan Kelelahan Perawat

\begin{tabular}{|c|c|c|c|c|c|c|c|}
\hline \multirow{3}{*}{ Beban Kerja } & \multicolumn{6}{|c|}{ Kelelahan Perawat } & \multirow{3}{*}{ Nilai $p$} \\
\hline & \multicolumn{2}{|c|}{ Kelelahan } & \multicolumn{2}{|c|}{ Tidak Lelah } & \multicolumn{2}{|c|}{ Total } & \\
\hline & $\mathrm{n}$ & $\%$ & $\mathrm{n}$ & $\%$ & $\mathrm{n}$ & $\%$ & \\
\hline Berat & 4 & 7.4 & 3 & 5.5 & 7 & 12.9 & \multirow{4}{*}{0.031} \\
\hline Sedang & 10 & 18.5 & 17 & 31.4 & 27 & 50 & \\
\hline Ringan & 2 & 3.7 & 18 & 33.3 & 20 & 37 & \\
\hline Total & 16 & 29.6 & 38 & 70.3 & 54 & 100 & \\
\hline
\end{tabular}

Sumber Data Primer: 2018
Uji statistik dengan menggunakan uji Chi Square diperoleh bahwa nilai p 0,031 $<\alpha 0,05$. Dengan demikian Ho ditolak dan Ha diterima, artinya ada hubungan antara beban kerja dengan kelelahan kerja perawat

\section{Pembahasan}

Berdasarkan hasil penelitian yang telah dilakukan pada 54 responden dimana diperoleh umur paling banyak perawat yaitu 26-35 tahun dimana diperoleh 32 responden, kemudian umur $>35$ tahun yaitu 4 responden dan sisanya $<26$ tahun yaitu 18 responden. Sedangkan kelelahan perawat dapat dilihat bahwa paling banyak tidak lelah yaitu 37 responden. Penelitian ini sejalan dengan penelitian sebelumnya mengenai usia, penelitian yang dilakukan oleh Suma'mur (2009) dimana diperoleh berdasarkan hasil uji Korelasi Spearman menunjukan bahwa nilai $\mathrm{p}$ value $0,001<$ 0,05 dan nilai $\mathrm{r}=0,391$ maka dapat dinyatakan ada hubungan yang lemah antara umur dengan kelelahan kerja pada perawat. Peneliti berasumsi bahwa semakin tua seseorang maka akan mempengaruhi kualitas kerja seseorang dimana didalamnya termasuk dalam melaksanakan tugas, karena semakin tua organ-organ yang ada dalam tubuh seseorang juga mengalami perubahan, namun ada juga responden yang termasuk kategori tua namun tidak mengalami kelelahan, hal ini dapat disebabkan karena responden memanfaatkan waktu istirahatnya dengan baik. Selain itu pada kategori umur muda juga terdapat responden yang juga mengalami kelelahan kerja. Berdasarkan hasil wawancara, responden tersebut memiliki pola tidur yang kurang baik. Dan juga kebiasaan yang menghabiskan waktu hingga larut malam setelah pulang kerja. Hasil

penelitian yang telah dilakukan pada 54 responden dimana diperoleh lama kerjapada perawat paling banyak $<5$ tahun dimana diperoleh 37 responden dan $>5$ tahun 17 responden. Sedangkan kelelahan 
perawat dapat dilihat bahwa paling banyak tidak lelah yaitu 37 responden dan sisanya menunjukan adanya kelelahan yaitu 17 responden. Dari hasil analisis data ChiSquare diperoleh nilai $\mathrm{p}=0,114<\alpha=0,0$ yang menunjukan tidak adanya tingkat hubungan antara variabel bebas dan variabel terikat. Hal ini sejalan dengan penelitian yang dilakukan oleh Setiadi ( 2013) dimana hasil uji Chi-Square didapatkan nilai signifikan adalah $\mathrm{p}=$ 0,114 maka Ho diterima dan H1 ditolak. Jadi tidak terdapat hubungan antara masa kerja dengan kelelahan kerja di Rumah sakit Umum daerah Noongan Kecamatan Langowan Barat Kabupaten Minahasa.

Peneliti berasumsi responden dengan masa kerja $<5$ tahun dan $>5$ tahun tidak beresiko mengalami kelelahan kerja, hal ini disebabkan karena beberapa faktor, misalnya umur, beberapa responden telah bekerja > 5 tahun tapi umurnya masih tergolong muda, jadi masa ketahanan tubuh dan fisiknya masih kuat sehingga responden tidak mudah lelah, faktor lainya, seperti asupan energi dalam tubuhnya baik, dan responden dengan masa kerja yang lama lebih berpengalaman, sehingga mereka mengetahui posisi kerja yang baik atau nyaman untuk dirinya hal tersebut diperkirakan dapat mencegah atau mengurangi terjadinya kelelahan kerja.

Hasil penelitian yang telah dilakukan pada 54 responden dimana diperoleh lama beban kerja perawat paling banyak sedang yaitu 27 responden dan paling sedikit beban kerja berat yaitu 7 responden, sedangkan kelelahan perawat dapat dilihat bahwa paling banyak tidak lelah yaitu 37 responden dan sisanya menunjukkan adanya kelelahan yaitu 17 responden. Dari hasil tebel silang dimana dapat dilihat adanya hubungan yang bermakna antara lama kerja dengan kelelahan perawat dimana hal ini berdasarkan hasil analisis data uji Chi Square diperoleh nilai p 0,031 $<\alpha 0,05 y a n g$ menunjukkan adanya tingkat hubungan antara variabel bebas dengan variabel terikat.
Penelitian yang dilakukan oleh Rahmawati (2006), bahwa ada hubungan antara beban kerja dengan kelelahan kerja perawat sebesar 0,001 di RSUD Dr. Harjono Kabupaten Ponorogo. Penelitian tersebut didukung oleh berbagai penelitian yang meneliti tentang beban kerja fisik perawat. Berdasarkan penelitian yang dilakukan oleh Dewi P (2008), menunjukkan bahwa perawat di RS Adi Husada Undaan Wetan Kota Surabaya memiliki beban kerja fisik kategori sedang. Penelitian serupa juga dilakukan oleh Diana Sari (2013), bahwa beban kerja fisik yang dialami perawat di Instalasi Rawat Inap termasuk ke dalam kategori ringan dan sedang.

Berdasarkan hasil Penelitian, peneliti berasumsi bahwa beban kerja yang berat akan mempengaruhi kelelahan perawat juga, dimana jika pekerjaan yang harus diselesaikannya begitu banyak maka memerlukan waktu dan tenaga yang cukup banyak juga untuk menyelesaikannya, dengan demikian akan membuat seseorang merasakan kelelahan dalam melakukan pekerjaan. Namun terdapat juga responden yang memiliki beban kerja ringan tetapi mengalami kelelahan, hal ini dipengaruhi oleh beberapa faktor misalnya usia, beberapa responden telah berusia > 35 tahun usia sangat berkaitan dengan kinerja karena pada usia yang meningkat akan terjadi penurunan kemampuan organ, tubuh memerlukan energi yang lebih sehingga denyut nadi semakin meningkat dan membutuhkan waktu istirahat yang lebih, faktor lainya seperti asupan energi dalam tubuhnya kurang baik sehingga responden mudah mengalami kelelahan

\section{SIMPULAN}

Berdasarkan hasil penelitian yang dilakukan di ruang rawat inap Rumah Sakit Umum GMIM Pancaran Kasih Manado, faktor usia paling banyak menunjukkan 26-35 tahun, masa kerja paling banyak < 5 tahun, dan beban kerja perawat paling banyak berada pada kategori sedang, 
sedangkan kelelahan perawat menunjukkan paling banyak tidak lelah, dan adanya hubungan usia dengan kelelahan kerjaperawat, tidak Terdapat adanya hubungan masa kerja dengan kelelahan kerja perawat, terdapat hubungan beban kerja dengan kelelahan kerja perawat di RSU GMIM Pancaran Kasih Manado.

\section{DAFTAR PUSTAKA}

Anis Wahyuningsih, (2003). Tingkat Kepuasan Konsumen Berdasarkan Kualitas Pelayanan Pada RSU Kanupateri (SKRIPSI), Karanganyar. Muhammadiyah Surakarta.

Baiduri,(2008). Kaidah Dasar Penerapan Kesehatan Dan Keselamatan Kerja. Jakarta :Universitas Indonesia Press.

Barokah, 2017. Analisis Laporan Keuangan Untuk Menilai Kinerja Perusahaan Daerah Air Minum Tirta Binangun Kabupaten Kulon Progo. Tugas Akhir. Universitas Negeri Yogyakarta.

Dewi, P. (2008). Pemisahan Minyak Atsiri Daun Kemangi (olimumbasilirum) Secara KLT dan Aktifitas Terhadap sMalazeria Fastur in Vitro, Skripsi, Fakultas Kedokteran, Universitas Diponegoro.

Diana Sari (2003). Konsep Dasar dan Aplikasi, Edisi ke-2 Guna Widya Surabaya.

Depkes RI, 2009. Sistem Kesehatan Nasional. Jakarta.

Eraliesa, (2008). Hubungan Faktor Individu dengan Kelelahan Kerja pada Tenaga Kerja Bongkar Muat di Pelabuhan Tapaktuan Kecamatan Tapaktuan Kabupaten Aceh Selatan.
Skripsi tidak diterbitkan. Medan: Fakultas Kesehatan Masyarakat, Universitas Sumatera Utara.

Haryono,dkk,(2009). Akuntansi Sektor Publik. Yogyakarta: AndiOfset.

ILO, (2003).Encyclopedia of Occupational Health and Safety.Penerbit : Geneva

Kemenkes RI, (2016). Pedoman Gizi Seimbang. http://gizinet.org.id/PGS. [Accessed 21 Juli 2018].

Nursalam. (2008). Konsep dan Penerapan Metodologi Penelitian Ilmu Keperawatan : Jakarta: Salemba Medika

Nursalam. (2016). Metodologi Penelitian Ilmu Keperawatan: Pendekatan Praktis. Ed. 4, Jakarta: Salemba Medika

Nurmianto, (2005).Ergonomi, Konsep Dasar dan aplikasinya. Guna Widya Jakarta.

Rahmawati, dkk. 2006. Pengaruh Asimetri Informasi Terhadap Praktik Manajemen Laba Pada perusahaan Perbankan Publik Yang Terdaftar di Bursa Efek jakarta, Simposium Nasional Akuntansi IX

Setiadi. (2013). Metode Penelitian Kuantitatif dan Kualitatif. Bandung : Alfabeta.

Suma'mur. (2009). Hiegiene Perusahaan dan Keselamatan Kerja. Jakarta : CV Sagung Seto.

World Health Organization (WHO) 2014. Commission on Ending Childhood Obesity.Geneva, World Health Organization, Departemen of 
e-Journal Keperawatan (e-Kp) Volume 7 Nomor 1, Mei 2019

Noncommunicable disease surveillance.

WHO. World Health Organization LGBT

Report: Global health.Gov;2016

Availablefrom:http://www.globalhealth.

Gov/global-health-

topics/lgbt_report.html. 